\title{
Automotive Bolts Tightening Analysis using Contact Stress Simulation: Developing An Optimal CAE Design Approach Model
}

Takehiro Onodera, Aoyama Gakuin University, Japan Kakuro Amasaka, Aoyama Gakuin University, Japan

\begin{abstract}
In recent years, enhancing computer-aided engineering (CAE) analysis is the most pressing issue facing companies seeking to implement development design that results in high quality and shortened delivery times. This paper presents an "Optimal CAE Design Approach Model" that can be used to reform the business processes associated with development design. The model consists of the following steps: (1) defining the problem, (2) conducting prototype testing, (3) visualizing the problem, (4) employing the CAE technological element analysis model, (5) conducting a two-dimensional CAE analysis, (6) conducting a three-dimensional CAE analysis, (7) carrying out a predictive evaluation, (8) optimizing the design, and (9) verifying the results. As a specific application for this process, the authors focused on the ongoing problem of bolt loosening at automakers, using the model to explain the loosening mechanism by analyzing the contact stress at the bearing surfaces in bolted parts and gain new knowledge.
\end{abstract}

Keywords: CAE; Optimal CAE Design Approach Model; Bolt Loosening

\section{INTRODUCTION}

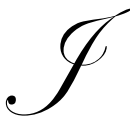
apanese automakers are renowned the world over for their production methods. In recent years, these automakers have been faced with the urgent task of drastically reduced their development design times in order to respond quickly to changing consumer needs. One of the most important challenges for manufacturers is strengthening and enhancing computer-aided engineering (CAE) methods of analysis in order to achieve quality development design processes that are also very brief(K. Amasaka, 2007; K. Amasaka, 2008 ; K. Amasaka, 2010; K.Amasaka, 2012). To address these issues, the authors conducted research on an "Optimal CAE Design Approach Model" and applied it to nut bearing surfaces on bolted parts. This paper discusses a portion of that research.

\section{CAE ANALYSIS: CURRENT STATUS AND RESEARCH AIMS}

Since today's analysis methods depend heavily on analytical engineers' unspoken experiential knowledge or rules of thumb, analytical accuracy varies. Therefore, there is an urgent need to establish a more precise form of CAE analysis which is capable of producing results that consistently match those obtained through prototype testing(K. Amasaka, 2007; K. Amasaka, 2008; K.Amasaka, 2012; Whaley, R.C., et al., 2000; Alba, E., 2005).

More specifically, manufacturers could cut back significantly on preproduction experiments if the discrepancy (or gap) between prototype testing and CAE analysis results was brought to around 5\%. In effect, this would eliminate the need for reworking, which would in turn shorten development design times and allow manufacturers to simultaneously achieve their quality, cost, and delivery (QCD) targets(K. Amasaka, 2007 ; K. Amasaka, 2008; K. Amasaka, 2010; K.Amasaka, 2012; Whaley, R.C., et al, 2000; Alba, E., 2005). 
In response to the above challenges, the authors worked to develop an "Optimal CAE Design Approach Model" that makes use of both numerical simulation (CAE) and statistical science (SQC) (K. Amasaka, 2007; K. Amasaka, 2008; K. Amasaka, 2010; K. Amasaka, 2012). In the course of developing this model, the authors applied it to several bottleneck technologies in the auto industry, including predicting and controlling the special characteristics of automobile lifting power, anti-vibration design of door mirrors, urethane seat foam molding, oil seal leaks in the drive train, and bolt tightening. In all of these applications, the given results were obtained(K. Amasaka, 2007; K. Amasaka, 2008;T. Ito,et al,2010; T. Takahashi,et al, 2010; T. Ueno, et al, 2009; H. Yamada. and K. Amasaka, 2011).

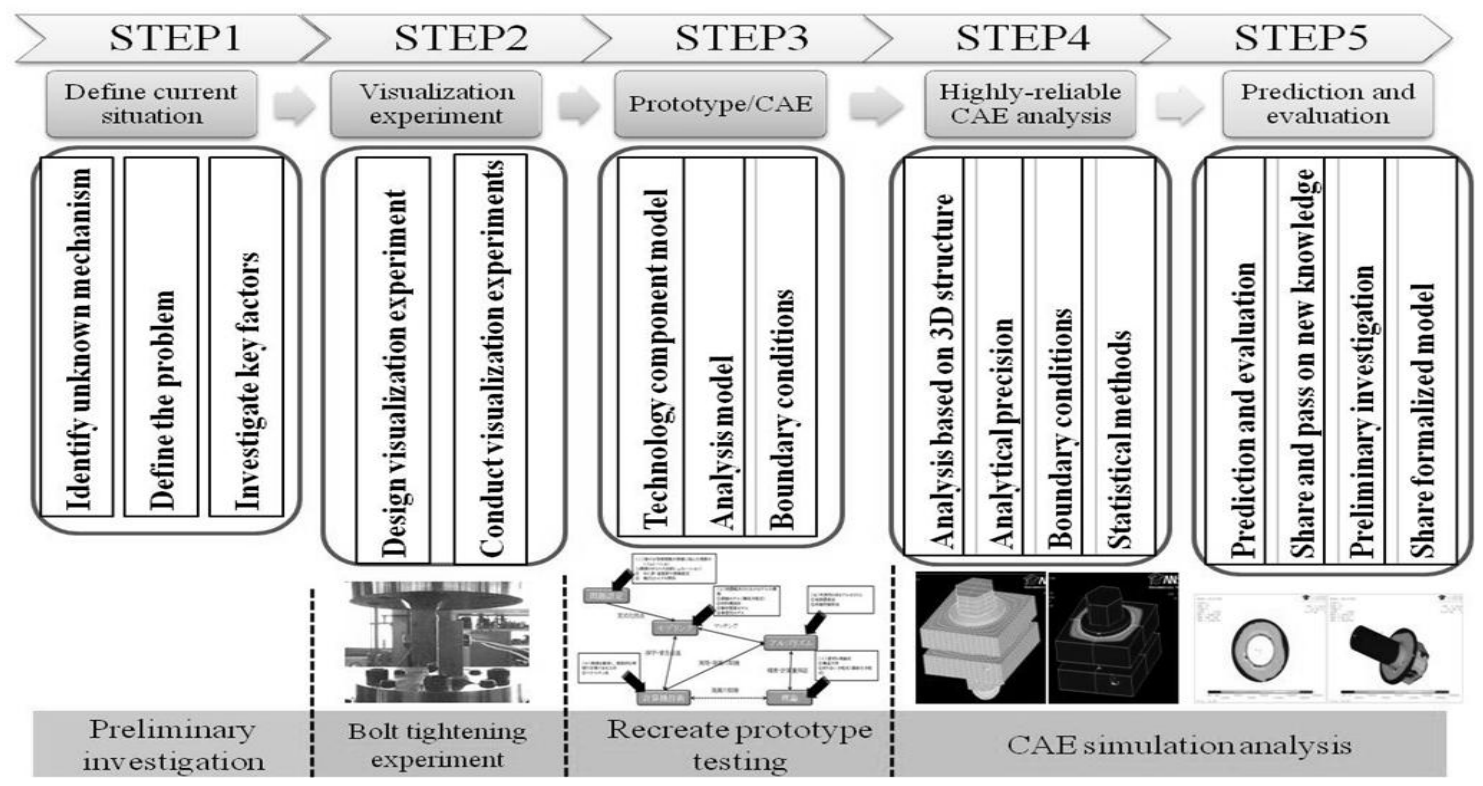

Figure 1: Optimal CAE Design Approach Model

This paper uses the knowledge gained through the authors' previous efforts to propose an "Optimal CAE Design Approach Model" that can be used to reform the business processes involved in development design. The model is then applied to the analysis of nut bearing surfaces on bolted parts, and its effectiveness is verified.

\section{AN OPTIMAL CAE DESIGN APPROACH MODEL}

This section presents an "Optimal CAE Design Approach Model" in Figure 1, which shows the procedural elements in steps one through five of the business process used in automotive development design.

\section{STEP 1: Define The Current Situation}

Step 1, defining the current situation, means explaining problematic technological issues where the number of functional breakdowns is not decreasing. The important task in this step is to clarify why the breakdowns are occurring as well as the mechanism that is generating them.

Experts inside and outside the company use their collective wisdom in collaborative activities, applying the latest statistical methods and investigating and analyzing complex cause-and-effect relationships to define the problem in minute detail and reason out the faulty mechanism. 


\section{STEP 2: Conduct A Visualization Experiment}

In step 2, the visualization experiment, prototype testing is conducted in order to visualize the mechanism (dynamic behavior) that is generating the defect. This is how the faulty mechanism is further defined.

Specifically, the Science SQC Approach Method - SQC Technical Method is applied to accurately explain the fault and conduct a factor analysis. This method uses N7 (seven new QC tools), SQC (general statistical methods), RE (reliability engineering), MA (multivariate analysis), and DE (design of experiment) (K. Amasaka, 2007; K. Amasaka, 2010; T. Ito,et al.,2010; T. Takahashi,et al.,2010; T. Ueno, et al., 2009; H. Yamada. and K. Amasaka, 2011 ).

The use of this method allows the discovery of previously overlooked and unidentified latent factors and the faulty mechanism to be demonstrated via a logical thought process.

\section{STEP 3: Aligning Prototype Testing And CAE}

In step 3, the key factors (technology components) identified in steps 1 and 2 that are generating the fault are subjected to a numerical simulation. The simulation makes it possible to match results obtained through prototype testing and CAE analysis using absolute values, values for which there is no discrepancy between the two methods(K. Amasaka, 2007; K. Amasaka, 2010; T. Takahashi,et al, 2010; T. Ueno, et al, 2009; H. Yamada. and K. Amasaka, 2011 ).

More specifically, a three-dimensional model is created using CAD (3D). At this point, all business processes are scientifically and comprehensively optimized using the following steps, which must be part of a high quality CAE analysis: define the phenomenon, theory, algorithm, modeling, calculation precision(K. Amasaka, 2007; K. Amasaka, 2008; K. Amasaka, 2010).

In doing this, it is absolutely essential to clearly model the cause-and-effect relationships in unexplained mechanisms identified during prototype testing (visualization). When implementing this step for problems like oil seal leaks or bolt tightening (T. Ueno,et al, 2009), for example, it is important to clarify boundary and contact conditions.

In order to conduct a precise numerical simulation, there must be both an accurate theory and an experimental model that can logically define the impact of the latent factors identified during the experiment. Selecting a model with logical calculation procedures, analytical modeling, and algorithms is a must, with the goal of qualitatively modeling the fault (mechanism).

\section{STEP 4: Conduct A Highly-reliable CAE Analysis}

In step 4, conducting a highly-reliable CAE analysis, a highly reliable numerical simulation (quantitative modeling/ high quality CAE analysis) is conducted. This makes it possible to predict and control the absolute values needed for the CAE analysis based on the knowledge gained in step 3. In the above case, a mesh was created using optimization and contact conditions were defined.

\section{STEP 5: Predict And Evaluate}

Highly reliable CAE analysis makes CAE analysis for predictive evaluation possible when carrying out the business processes in steps 1 through 4 in minute detail. In the past, CAE modeling was often conducted in an illogical way, with conventional CAE analysis and an undefined faulty mechanism. The result was a significant discrepancy (10-30\%) between prototype testing and CAE analysis values, often confining the use of CAE analysis to the auxiliary monitoring task of comparative evaluations of old and new products(K. Amasaka, 2007; K. Amasaka, 2008; K. Amasaka, 2010). 
CAE analysis for predictive evaluation (steps 1 through 4) makes precise prediction and evaluation possible by pinpointing key factors, accurately identifying the development design factors that must be optimally controlled, and making them explicit by incorporating them into drawings and manufacturing techniques. This contributes to swift design development that includes the generation of new knowledge, new design ideas, sharing of explicit models, and creating assets out of new technology that gets passed on and developed(K. Amasaka, 2005; K. Amasaka, 2007; K. Amasaka, 2008; K. Amasaka, 2010; T. Ito,et al, 2010; T. Takahashi,et al, 2010; T. Ueno,et al, 2009; H. Yamada. and K. Amasaka, 2011).

\section{APPLICATION: ANALYZING NUT BEARING SURFACES IN BOLTED PARTS USING CAE}

This section presents further research on bolted parts, applying the proposed model to nut bearing surfaces in order to verify its effectiveness(T. Fukuoka,et al, 2006; M. Zhang,et al, 2004; S. Izumi,et al, 2005; T. Onodera and K. Amasaka, 2011).

\section{Bolts and Nuts Used}

A bolt tightening experiment was conducted using hexagonal bolts and nuts equipped with a flange. The pitch was the maximum and minimum size that could be used in manufacturing: $0.50 \mathrm{~mm}$ (Figure 2) and $1.75 \mathrm{~mm}$ (Figure 3).

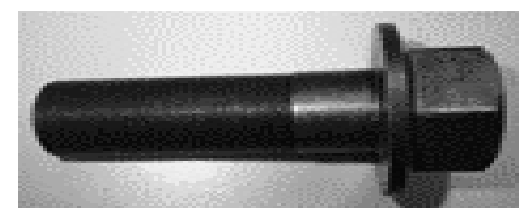

Figure 2: Pitch $0.50 \mathrm{~mm}$

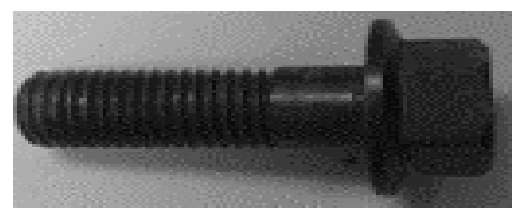

Figure 3: Pitch 1.75mm

\section{The Bolt Tightening Experiment}

In order to estimate the vibration load to be used in the vibration experiment, a static experiment was carried out. In the static experiment, a bolted workpiece was subjected to a tightening load of $20 \mathrm{kN}$ and $35 \mathrm{kN}$, and the load that rapidly increased bearing surface slippage was measured on a testing apparatus.

Specifically, vibration was displaced by applying external force to the upper vibrating jig perpendicular to the axis. The tightening load on the bolt was measured and changes in the tightening load due to displacement were checked. The testing apparatus was then vibrated with a vibration load of $\pm 90 \%$ of the measured static release load. Surface slippage repeatedly occurred, resulting in loosened bolts. Changes in the placement of the bolts/testing apparatus as well as in bolt tightening load were measured based on the number of repetitions. 


\section{Numerical Simulation}

\section{Technological Element Model (Brief Summary)}

In conducting a high quality CAE analysis, the first step is to define the problem that needs to be solved and then model it using some kind of numerical formula. A computer is then used to analyze the model using an algorithm (calculation procedure). The appropriateness, applicable scope, and performance of the algorithm itself are developed based on theory, and the computer technology (calculation technique) is able to actually perform the calculations. The relationship among these factors is indicated in the technological element model (Figure 4).

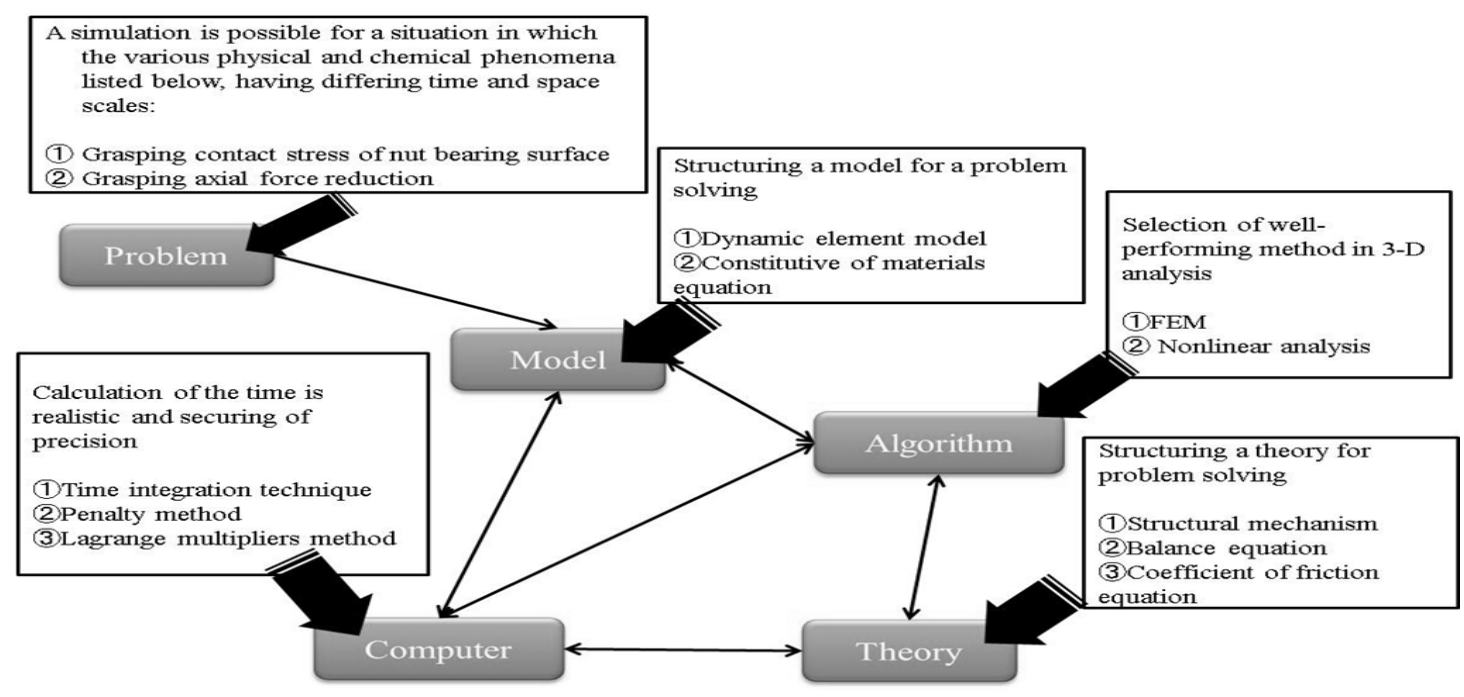

Figure 4: Technological Element Model

\section{CAE Analysis Of Nut-bearing Surfaces}

The CAE analysis of nut bearing surfaces uses a three-dimensional model to conduct a finite element analysis. The model takes into consideration the structure of the bolt threads and identifies the response on the nut bearing surface. The three-dimensional finite element model creates a detailed mesh showing the area around the bolt/nut and areas of contact.

The analysis procedure is conducted in the next step. First, the two bolted workpieces are placed between the bolt and the nut. Axial force is applied to the bolt (securing the edge of the lower piece) and perpendicular to the upper piece. Finally, the analysis looks at the pressure on the contact surface (between the bolt/nut bearing surface and the workpieces and between the bolt threads and the nut) and at the behavior of the pieces in terms of reduction in axial force when pressure changes.

Figures 5 and 6 show the analysis results when force is applied perpendicular to the upper workpiece and axial force release load is applied to workpiece on the nut side. Both figures show a lack of uniformity in terms of nut bearing surface response and a localized strong response where the nut thread structure begins. In looking at the differences between the two pitch values, the response distribution is more concentrated around the initial thread structure on the bolt with the longer pitch $(1.75 \mathrm{~mm})$.

These results suggest that differences in pitch also lead to differences in non-uniformity on nut bearing surfaces and a more pronounced gap between areas of strong and weak response. In terms of new information, the analysis revealed that the length of bolt and nut pitch impacts the reduction in contact force on contact surfaces. 


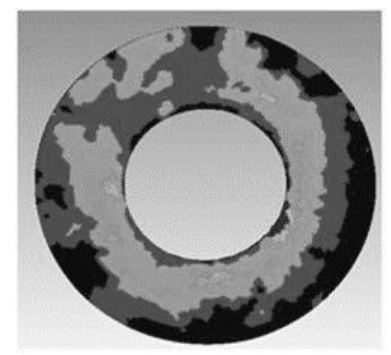

Figure 5: Pitch 0.50mm

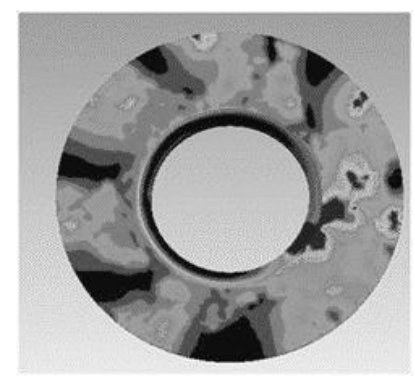

Figure 6: Pitch $1.75 \mathrm{~mm}$

\section{Comparing The Results}

Comparing the axial force reduction behavior measurements obtained through prototype testing and those obtained through CAE analysis verified the precision of the CAE analysis results. Figure 7 compares the results of prototype testing and CAE analysis for the bolt and nut with $1.75 \mathrm{~mm}$ pitch under a fastener load of $35 \mathrm{kN}$. The dashed line shows a margin of error of 3\%, indicating that a high quality CAE analysis was achieved. Similar results were achieved for the $0.50 \mathrm{~mm}$-pitch bolt and nut as well.

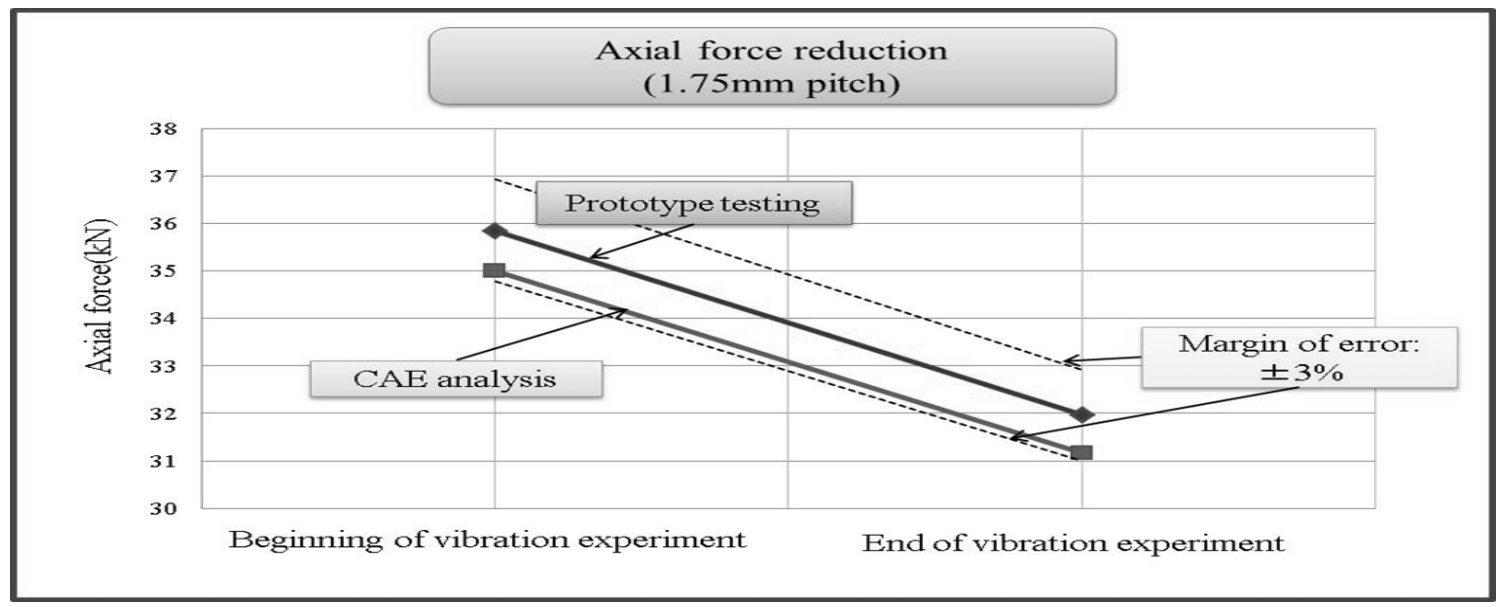

Figure 7: Comparing The Results 


\section{CONCLUSION}

This paper proposes an "Optimal CAE Design Approach Model" that contributes to shorter development design times. The model was applied to the pressing issue of nut bearing surfaces on bolted parts and the given results were obtained.

\section{AUTHOR INFORMATION}

Takehiro Onodera is a graduate student of the College of Science and Engineering at Aoyama Gakuin University.

Dr. Kakuro Amasaka is a Professor in the College of Science and Engineering at Aoyama Gakuin University, Japan. He received his Ph.D. degree in Precision Mechanical and System Engineering, Statistics and Quality Control at Hiroshima University in 1997. Since joining Toyota Motor Corporation in 1968, He worked as a quality control consultant for many divisions, and the General Manager of the TQM Promotion Division (1998-2000). His specialty is New JIT, Science TQM, Science SQC, Numerical Simulation (CAE) and Customer Science. Now, He has been serving as the chairman of JOMSA (2010-). E-mail: Kakuro_amasaka@ @ise.aoyama.ac.jp. Corresponding author.

\section{REFERENCES}

1. Alba, E. (2005), Parallel Met5ahuuristics: A new class of algorithms, Addison Wiley.

2. Amasaka, K. (2005), Science SQC, New Quality Control Principle - The Quality Control of Toyota, Springer.

3. Amasaka, K. (2007), Highly Reliable CAE Model, The Key to Strategic Development of Advanced TDS , Journal of Advanced Manufacturing Systems, vol.6, no.2, pp.159-176.

4. Amasaka, K. (2008), An Integrated Intelligence Development Design CAE Model Utilizing New JIT, Application to. Automotive High Reliability Assurance, Journal of Advanced Manufacturing Systems, vol.7, no.2, pp.221-241.

5. Amasaka, K. (2010), Proposal and Effectiveness of a High Quality Assurance CAE Analysis Model: Innovation of Design and Development in Automotive Industry, Current Development in Theory and Applications of Computer Science, Engineering and Technology, vol.2, no.1/2, pp.23-48.

6. Amasaka, K. (2012), Constructing Optimal Design Approach Model: Application on the Advanced TDS, Journal of Communication and Computer.(decided to be published)

7. Fukuoka, T., Nomura, M. and Morimoto, Y. (2006), Proposition of Helical Thread Modeling with Accurate Geometry and Finite Element Analysis, Transactions of the Japan Society of Mechanical Engineers, Series A, vol.72, no.723, pp.1639-1645.

8. Ito, T., Sato, M., Yamaji, M. and Amasaka, K. (2010), An Analysis of Bottleneck Technology by using Experiments and CAE: Example of the Automotive Transaxle Oil Seal Leakage, International Business \& Economics Research Journal, vol.9, no.12, pp. 123-129.

9. Izumi, S., et al., (2005), Three-dimensional Finite Element Analysis on Tightening and Loosening Mechanism of Bolted Joint, Transactions of the Japan Society of Mechanical Engineers, Series A, vol.71, no.702, pp.204-212.

10. Onodera, T. and Amasaka, K. (2011), A Study on a High Quality CAE Analysis Approach Model Automotive Bolts Tightening Analysis using Contact Stress Simulation-, Proceedings of International Symposium on System Integration, Kyoto University, Kyoto, Japan, pp.1379-1382.

11. Takahashi, T., Ueno, T., Yamaji, M. and Amasaka, K. (2010), Establishment of Highly Precise CAE Analysis Model -An Example the Analysis of Automotive Bolts-, The International Business \& Economics Research Journal, vol. 9, no.5, pp. 103-113.

12. Ueno, T., Yamaji, M, Tsubaki, H. and Amasaka, K. (2009), Establishment of Bolt Tightening Simulation System for Automotive Industry Application of the Highly Reliable CAE Model, International Business \& Economics Research Journal, vol.8, no.5, pp.57-67.

13. Whaley, R. C., et al., (2001), Automated Empirical Optimization of Software and the ATLAS Project, Parallel Computing, vol.27, no.1-2, pp.3-35. 
14. Yamada, H. and Amasaka, K. (2011), Highly-Reliable CAE Analysis Approach- Application in Automotive Bolt Analysis, China-USA Business Review and Chinese Business Review, vol.10, no.3, pp.199- 205.

15. Zhang, M. and Jiang, Y. (2004), Finite Element Modeling of self-Loosening of Bolted Joints, Analysis of Bolted Joints, ASME Journal of Mechanical Design, vol.478, pp.19-27. 